\title{
POR UMA PEDAGOGIA QUE FALE EM NOME PRÓPRIO
}

\author{
FOR A PEDAGOGY THAT SPEAKS IN ITS OWN NAME
}

POR UMA PEDAGOGÍA QUE HABLE POR SI SOLA

\author{
Ana Paula Crizel \\ Angélica Vier Munhoz
}

\begin{abstract}
RESUMO
Trata-se de pensar uma pedagogia que fale em nome próprio. Tal proposição fez parte das investigações da dissertação de mestrado vinculada ao Programa de Pós-Graduação em Ensino da Univates, que tinha como objetivo pensar diferentemente o território da pedagogia. Dessa necessidade, dá-se um encontro - nome próprio , expressão encontrada em meio aos escritos de Deleuze e Guattari. Do encontro, cria-se o desejo de pensar uma pedagogia que fale em nome próprio. O primeiro movimento feito foi rastrear, na obra Mil Platôs, as aparições da expressão e estabelecer alguns marcadores nos excertos selecionados, na intenção de apreender de que maneira essa noção é compreendida e operada pelos autores. No segundo momento do texto, tensionam-se as formas e formações da pedagogia para, na sequência, propor a composição de uma expressão que opera no plano filosófico com o território da pedagogia. Ao finalizar, conclui-se que tal composição, ao acontecer, movimenta o corpo e o pensamento, criando condições para um possível.
\end{abstract}

PALAVRAS-CHAVE: Pedagogia. Nome. Movimento. Formação.

\section{ABSTRACT}

This paper aims to think about a pedagogy that speaks in its own name. Such proposition was part of investigations carried out for a master's dissertation linked to the Post-Graduation Program in Teaching at Univates that aimed to think differently about the pedagogy territory. From that need, an encounter derived own name -, an expression found amidst Deleuze and Guattari's writings. From that encounter, emerges the desire to think a about a pedagogy that speaks in its own name. The first move is to map in A Thousand Plateaus the appearances of that expression and establish some markers in the selected excerpts in order to apprehend the way in which such notion is understood and operated by the authors. In the second part of the text, forms and formations of pedagogy are problematized, and we propose the composition of an expression that operates in the philosophical field with the pedagogy territory. Finally, we conclude that when such composition occurs it moves both the body and the thought, thus creating conditions for something possible.

KEYWORDS: Pedagogy. Name. Movement. Education.

\section{RESUMEN}

Se trata de pensar en una pedagogía que hable por sí misma. Esta proposición formó parte de las investigaciones de disertación de la maestría vinculada al Programa de Pos-Graduación en Enseñanza de la Univates, que tenía como objetivo pensar el territorio de la pedagogía de manera diferente. De esta necesidad, se da un encuentro por sí misma - expresión que se encuentra en medio de los escritos de Deleuze y Guattari. Del encuentro, se crea el deseo de pensar en una pedagogía que hable por sí sola. El primer movimiento realizado fue rastrear, en la obra Mil Mesetas, las apariciones de la expresión y establecer algunos marcadores en torno a los extractos seleccionados, con la intención de aprender de que manera esa noción es comprendida y operada por los autores. En el segundo momento del texto, se tensionan las formas y formaciones de la pedagogía para, a continuación, proponer la composición de una expresión que opera en el plano filosófico como así también en la pedagogía. Se concluye que tal composición, al acontecer, mueve el cuerpo y el pensamiento, creando condiciones para algo posible.

PALABRAS-CLAVE: Pedagogía. Nombre. Movimiento. Formación. 


\title{
1 INTRODUÇÃO
}

Trata-se de uma composição. Uma composição improvável entre a noção de 'nome próprio', encontrada ao acaso em meio às obras de Deleuze e Guattari, e a 'pedagogia', um saber específico, legítimo e legitimado. Um acaso que, ao acontecer, cria a necessidade de tal composição: pensar uma pedagogia que fale em nome próprio. Da pedagogia porque foi nesse território que se instalaram as investigações da dissertação de mestrado vinculada ao Programa de Pós-Graduação em Ensino da Univates, desenvolvida no período de janeiro de 2014 a dezembro de 2015, da qual este artigo faz parte e traz alguns recortes. A escolha por esse território deu-se por dois motivos: primeiro, por ser o território de formação da pesquisadora e, segundo, por desejar pensar de outros modos tal domínio, buscando escapar de representações e comparações ou simplesmente manter-se na estabilidade de suas formas e formações, desenhadas na Modernidade.

$\mathrm{Na}$ intenção de fazer ver tais aproximações, no primeiro momento, apresenta-se de que maneira a noção de 'nome próprio' aparece e se articula nos textos de Deleuze e Guattari, especialmente nos cinco volumes da obra 'Mil Platôs: Capitalismo e Esquizofrenia'. Para isso, excertos foram colecionados, bem como foram criados alguns marcadores e agrupamentos como uma tática de mostração, uma espécie de contorno necessário para dar conta de um rastro intensivo, pois em nenhum momento a noção de 'nome próprio' aparece em definição, somente em operação e avizinhamento com outros conceitos, dando consistência a ambos. No segundo momento, tensiona-se o território da 'pedagogia' a partir de sua movimentação entre formas e forças para, na sequência, tecer aproximações entre a noção de 'nome próprio' e o território da 'pedagogia'. Uma composição improvável e, ao mesmo tempo, impossível, mas que, por assim ser, cria condições para um possível (DELEUZE, 1992) - pensar uma pedagogia que fale em nome próprio.

\section{NOME PRÓPRIO: ALGUNS RASTROS}

\begin{abstract}
Dizer algo em nome próprio é muito curioso, pois não é em absoluto quando nos tomamos por um eu, por uma pessoa ou um sujeito que falamos em nosso nome. Ao contrário, um indivíduo adquire um verdadeiro nome próprio ao cabo do mais severo exercício de despersonalização, quando se abre às multiplicidades que o atravessam de ponta a ponta, às intensidades que o percorrem. (DELEUZE, 1992, p. $15)$.
\end{abstract}

Falar em nome próprio, para Deleuze (1992), em nenhum momento é assumir-se por um eu, uma identidade, mas justamente o seu contrário. Falar em nome próprio torna-se um exercício de despersonalização, ou seja, quando nos deixamos atravessar pelas forças intensivas que nos interpelam ao longo de uma vida, em um esforço de composição com essas forças, fazendo, a todo momento, deformações nessa forma-eu que nos enclausura. Contudo, Deleuze (1992) faz uma ressalva: essa despersonalização não se dá por submissão, mas por amor.

Tal encontro com a expressão - nome próprio - dá-se em meio a livros, textos e leituras de Deleuze e Guattari. Esse encontro afecta e pulsa, pois fragiliza os convencionais 
entendimentos do que venha a ser um nome próprio. Encontrar, conforme Deleuze e Parnet (1998, p. 15), "é achar, é capturar, é roubar, mas não há método para achar, nada além de uma longa preparação". Dessa maneira, a leitura dispersa e a intenção de pensar por outras vias o território da pedagogia, espaço de investigação desta escrita, criaram condições para um encontro.

Desse encontro, surge a necessidade de rastrear essa expressão e compreender de que maneiras ela se articula e é operada nas demais obras de Deleuze e Guattari. Para isso, cria-se uma delimitação, opta-se por rastrear essa expressão nos cinco volumes do livro 'Mil Platôs: Capitalismo e Esquizofrenia'i (1995; 1995b; 1996; 1997; 1997b). Essa obra foi escolhida justamente por ter sido escrita a dois, entre o que se passou entre Deleuze e Guattari nesse processo de criação - não mais um ou outro, mas um agenciamento. É um rastreio porque não se sabia em qual platô ou de qual conceito tal expressão se aproximava; ela de repente saltava, pulava, aparecia e logo depois sumia em meio ao emaranhado de linhas e conceitos de uma página. Assim, o nome próprio foi muito mais encontrado do que procurado. Além disso, a coleção de excertos tinha a intenção de rastrear não só a expressão no seu contexto, mas também a intensidade de seus rastros.

Com a coleção de rastros, percebe-se que, em nenhum momento, essa noção de nome próprio se apresenta em definição; ela sempre aparece dispersa e em operação com os conceitos que atravessam cada platô. Por esse motivo, compreende-se que a expressão nome próprio não é tomada pelos autores enquanto um conceito, mas muito mais uma noção, um fluxo intensivo que faz composição com os conceitos criados por eles, dando consistência tanto para a expressão quanto para os conceitos.

Por não haver uma definição precisa do que venha a ser o nome próprio para Deleuze e Guattari, criam-se, a partir da coleção de excertos, alguns marcadores na intenção de agrupar esses rastros, pois se deseja, com eles, pensar uma pedagogia que fale em nome próprio. Tais marcadores, embora separados, muito mais por uma estratégia didática do que por assim serem percebidos, não pretendem chegar a uma definição precisa e limitada do que venha a ser um nome próprio.

A vontade e necessidade de tal movimento deram-se pelas afecções que tal encontro provocou no corpo e no pensamento, alimentando o desejo de pensar diferentemente. $\mathrm{Na}$ intenção de fazer ver em operação os movimentos da noção de nome próprio, na sequência, apresentam-se os marcadores estabelecidos em torno da coleção de excertos recolhidos.

Primeiro marcador: falar em nome próprio torna-se um "exercício de despersonalização"

Com efeito, se o nome próprio não indica um sujeito, não é tampouco em função de uma forma ou de uma espécie que um nome pode tomar um valor de nome próprio. O nome próprio designa antes algo que é da ordem do acontecimento, do devir ou da hecceidade. (DELEUZE; GUATTARI, 1997, p. 51-52).

Um nome próprio não indica um indivíduo, um sujeito ou um objeto, mas individuações. Falar em nome próprio torna-se um exercício de despersonalização \begin{tabular}{l|l|l|l|l|l|l}
\hline (C) ETD - Educ. Temat. Digit. & Campinas, SP & v.18 & n.4 & p. 942-954 & out./dez.2016 & ISSN 1676-2592
\end{tabular} 
(DELEUZE, 1992). Esse marcador foi delineado por ser recorrente nos excertos recolhidos. As palavras 'sujeito' e 'indivíduo' são insistentemente marcadas para fazer ver sua forma, que determina, marca e define jeitos de ser e relacionar-se com o mundo e as coisas - forma que, ao manter-se rija, não produz nome próprio, não pode ser nomeada. É pela despersonalização, pela diluição dessa formaii, a partir da composição com as forças que a atravessam, que “alguém pode ser nomeado" (DELEUZE; GUATTARI, 1995, p. 49).

Deleuze e Guattari (1995), ao escreverem sobre o rizomaiii, logo nas primeiras linhas, trazem o problema do nome e do EU. Escreveram a dois, mas também em vários, atravessados por seus intercessores, que por eles falam. EU, quem? Nenhuma necessidade de sabê-lo. "Não somos mais nós mesmos. Cada um reconhecerá os seus. Fomos ajudados, aspirados, multiplicados" (DELEUZE; GUATTARI, 1995, p. 11).

É visível que, em diferentes obras, se faz essa distinção entre a potência do nome próprio, que é atravessada pelas forças do fora, do sujeito, indivíduo, pessoa ou objeto, estes, enquanto um nome comum, uma forma dada que remete "a um ser ou objeto posto como único" (DELEUZE; GUATTARI, 1995, p. 41). Um nome próprio não opera por subjetividades, mas sim por individuações, acontecimentos, atravessamentos (DELEUZE; PARNET, 1998).

É possível perceber, nos excertos abaixo, o quanto a compreensão de nome próprio, desenvolvida pelos autores, escapa e dilacera o entendimento e uso comum dessa expressão, pois "adquire-se seu verdadeiro nome próprio" (DELEUZE; GUATTARI, 1995, p. 51) quando "o indivíduo se abre às multiplicidades que o atravessam de lado a lado" (Ibidem, p. 51), despersonalizando-se, deixando-se deformar pela força dos encontros que, ao acontecerem, arrebatam os sentidos e criam a necessidade de outras formações.

No livro Mil Platôs 2, ao desenvolverem um postulado sobre a linguística, Deleuze e Guattari (1995b) remetem-se ao nome próprio enquanto "matérias e funções" (Ibidem, p. 106), reforçando o desprendimento dessa noção das pessoas, sujeitos ou objetos.

Eis por que as máquinas abstratas possuem nomes próprios (e igualmente datas), que não designam mais certamente pessoas ou sujeitos, mas matérias e funções. $\mathrm{O}$ nome de um músico, de um cineasta, é empregado como o nome de um pintor que designa uma cor, uma nuance, uma tonalidade, uma intensidade: trata-se sempre de uma conjunção de Matéria e de Função (DELEUZE; GUATTARI, 1995b, p. 106).

Da mesma maneira, no platô $11^{\text {iv }}$, os autores tecem uma aproximação entre a noção de nome próprio e o conceito de território, um dos componentes do movimento do Ritornelo, ao reforçarem que o nome próprio é a marca constituinte de um domínio.

Essas qualidades são assinaturas, mas a assinatura, o nome próprio, não é a marca constituída de um sujeito, é a marca constituinte de um domínio, de uma morada. A assinatura não é a indicação de uma pessoa, é a formação aleatória de um domínio (DELEUZE; GUATTARI, 1997, p. 123). 
Percebe-se, a partir dos excertos desse marcador recortados para este artigo, que a noção de nome próprio busca fragilizar a noção de eu, sujeito, pessoa, esse aparato da linguagem que procura a unificação e a uniformização. Linguagem que nos constitui, nos produz e cria modos de posicionamento e deslocamento em um dado território.

\title{
Segundo marcador: um nome próprio é um complexo de multiplicidades intensivas
}

\begin{abstract}
A intensidade tem algo que ver com os nomes próprios, e estes não são nem representações de coisas (ou pessoas), nem representações de palavras. [...] Há uma espécie de nomadismo, de deslocamento perpétuo de intensidades designadas por nomes próprios, e que penetram umas nas outras ao mesmo tempo em que são vividas sobre um corpo pleno. A intensidade só pode ser vivida em relação com sua inscrição móvel sobre um corpo, e com a exterioridade movente de um nome próprio (DELEUZE, 2006, p. 325).
\end{abstract}

Um nome próprio, complexo de multiplicidades intensivas (DELEUZE; GUATTARI, 1995). Um nome próprio, como já referido, não designa um sujeito nem objeto, nenhum ser, um eu ou qualquer forma que esteja fixa em si e da qual derive o igual, idêntico, universal. Um nome próprio é pura intensidade, virtualidade que age sobre os corpos por meio da sensação, intensidade atravessada pelas multiplicidades apreendidas em um dado plano (DELEUZE; GUATTARI, 1995). Multiplicidade que "muda necessariamente de natureza à medida que ela aumenta suas conexões" (Ibidem, p. 17). Dessa maneira, um nome próprio não designa uma unidade, uma identidade, porque "todo nome próprio é coletivo" (DELEUZE; PARNET, 1998, p. 165). Um complexo de multiplicidades, sensíveis aos fluxos intensivos, está em constante metamorfose, diferença pura, "multiplicidades de multiplicidades" (DELEUZE; GUATTARI, 1995, p. 40).

No livro 'Mil Platôs 1', especialmente no platô $2^{v}$, em que os autores desenvolvem o conceito de multiplicidade a partir da imagem da 'matilha' e do 'homem dos lobos', a noção de nome próprio é insistentemente retomada, tanto que, nesse pequeno texto, muitos são os rastros encontrados. Rastros, literalmente. Seu rastro marca as intensidades de uma multiplicidade. Multiplicidades intensivas e móveis que operam por variação, escapando a uma forma, a uma identidade, vazando pelo meio, pelas linhas, sem fazer ponto, apenas mais linhas que, ao cruzarem-se, colocam em funcionamento seus agenciamentos.

O que é comprometido, tanto do lado das palavras quanto das coisas, é a relação do nome próprio como intensidade com a multiplicidade que ele apreende instantaneamente (DELEUZE; GUATTARI, 1995, p. 41).

O nome próprio é a apreensão instantânea de uma multiplicidade. O nome próprio é o sujeito de um puro infinitivo compreendido como tal num campo de intensidade. O Homem dos lobos, verdadeiro nome próprio, íntimo prenome que remete aos devires, infinitivos, intensidades de um indivíduo despersonalizado e multiplicado (DELEUZE; GUATTARI, 1995, 51).

Da mesma maneira, no platô $10^{\text {vi }}$, a noção de nome próprio é articulada ao conceito de devir. Na passagem, onde os autores retomam as obras de Virgínia Woolf, remetem a ela a potência de criar personagens que, com seus nomes próprios, são muito mais uma multiplicidade em devir do que meros sujeitos de uma ação/história. 
Em As ondas, Virgínia Woolf, que soube fazer de toda sua vida e sua obra uma passagem, um devir, toda espécie de devires entre idades, sexos, elementos e reinos, mistura sete personagens, Bernard, Neville, Louis, Jinny, Rhoda, Suzanne e Perceval; mas cada um desses personagens, com seu nome, sua individualidade, designa uma multiplicidade (por exemplo, Bernard e o cardume de peixes); cada um está ao mesmo tempo nessa multiplicidade e na borda, e passa a outras. Perceval é como que o último, envolvendo o maior número de dimensões (DELEUZE; GUATTARI, 1997, p. 36).

\section{Terceiro marcador: um nome próprio é sempre um coletivo de vozes}

As diferenças não passam entre individual e coletivo, pois não vemos qualquer dualidade entre os dois tipos de problemas; não há sujeito de enunciação, mas todo nome próprio é coletivo, todo agenciamento já é coletivo (DELEUZE; PARNET, 1998, p. 165).

Um nome próprio é sempre um coletivo de vozes (DELEUZE; GUATTARI, 1995b). Como mencionado no marcador anterior, um nome próprio é coletivo porque se torna uma multiplicidade atravessada por aquilo que a faz variar. Variação que corta pelo meio, fazendo criar outras conexões. Conexões sem eixo central, somente meios. E o nome próprio, por constituir-se sob essa velocidade, é um coletivo de vozes porque, conforme Deleuze e Guattari (1995, p. 50),

[...] não existe enunciado individual, mas agenciamentos maquínicos produtores de enunciados. [...] Cada um de nós é envolvido num tal agenciamento, reproduz o enunciado quando acredita falar em seu nome, ou antes fala em seu nome quando produz o enunciado.

Adquirimos um nome próprio quando, abertos para os encontros, nos deixamos afectar e nos tornamos outro. Outro de si, composto de muitos. Muitos que nos atravessam e nos constituem por meio de um movimento intensivo que, ao acontecer, recolhe e seleciona: vozes, ruídos, silêncios para produção de seus próprios enunciados.

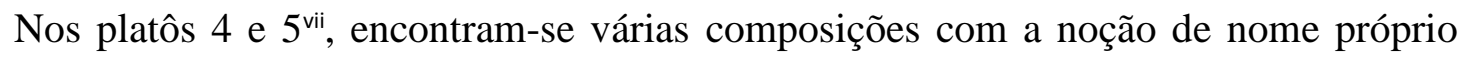
que se articulam com o terceiro marcador, justamente por tratar-se de um coletivo de vozes que não podem deixar de remeter-se aos regimes da linguagem que constituem os enunciados dessas vozes que atravessam e constituem os nomes próprios.

O discurso direto é fragmento de massa destacado, e nasce do desdobramento do agenciamento coletivo, mas este é sempre como o rumor onde coloco meu nome próprio, o conjunto das vozes concordantes ou não de onde tiro minha voz. Dependo sempre de um agenciamento de enunciação molecular, que não é dado em minha consciência, assim como não depende apenas de minhas determinações aparentes, e que reúne vários regimes de signos heterogêneos (DELEUZE; GUATTARI, 1995b, p. 25).

Não há como distinguir, portanto, uma língua coletiva e constante, e atos de fala, variáveis e individuais. A máquina abstrata é sempre singular, designada por um nome próprio, de grupo ou de indivíduo, ao passo que o agenciamento de enunciação é sempre coletivo, no indivíduo como no grupo (DELEUZE; GUATTARI, 1995b, p. 48).

Quarto marcador: um nome próprio é impessoal, infinitivo e indefinido 
São as hecceidades que se exprimem nos artigos e pronomes indefinidos, mas não indeterminados, em nomes próprios que não designam pessoas, mas marcam acontecimentos, em verbos infinitivos que não são indiferenciados, mas constituem devires ou processos. É a hecceidade que tem necessidade desse tipo de enunciação (DELEUZE; PARNET, 1998, p. 108).

Um nome próprio é impessoal $e$ infinitivo $e$ indefinido (DELEUZE; PARNET, 1998). Este último marcador faz composição com os demais. Marcador que sutilmente esboça as estratégias de um nome próprio. Conforme Deleuze e Parnet (1998, p. 95), a "lógica do artigo indefinido, do verbo infinitivo e do nome próprio", um agenciamento da própria língua para manter a impessoalidade de um nome, poder falar "por afectos, intensidades, experiências, experimentações" (DELEUZE, 1992, p. 15), sem precisar de um EU determinado, escapando de lembranças e histórias de vida, uma memória voluntária que em seu movimento produz o mesmo.

\footnotetext{
Plano de conteúdo e plano de expressão. Essa semiótica é sobretudo composta de nomes próprios, de verbos no infinitivo e de artigos ou de pronomes indefinidos. Artigo indefinido + nome próprio + verbo infinitivo constituem com efeito a cadeia de expressão de base, correlativa dos conteúdos minimamente formalizados, do ponto de vista de uma semiótica que se liberou das significâncias formais como das subjetivações pessoais (DELEUZE; GUATTARI, 1997, p. 50-51).
}

São os militares e os meteorologistas que têm os segredos dos nomes próprios, quando eles os dão a uma operação estratégica, ou a um tufão. O nome próprio não é o sujeito de um tempo, mas o agente de um infinitivo. Ele marca uma longitude e uma latitude (DELEUZE; GUATTARI, 1997, p. 51-52).

Todos os quatro marcadores conversam entre si, atravessam-se e, inclusive, retomam elementos um do outro a todo momento. Como foi mencionado no início deste movimento de mostração, a intenção de tais contornos foi muito mais uma tática de deslocamento por entre os fluxos e movimentos dessa expressão na obra Mil Platôs do que a proposição de uma delimitação precisa e estanque do que venha a ser um nome próprio para Deleuze e Guattari. A mostração desses excertos torna-se matéria que, ao ser deslocada de um plano filosófico para outro domínio, o da pedagogia, cria condições de pensá-la diferentemente. Porém, antes dessa composição incomum, apresenta-se como se compreende a pedagogia e criam-se alguns tensionamentos em torno de suas formas e formações, problematização necessária para abrir algumas fissuras na estabilidade de seus movimentos/deslocamentos.

\section{TERRITÓRIO DA PEDAgOGIA: MOVIMENTAÇÃO POR ENTRE FORMAS E FORÇAS}

Compreende-se, neste artigo, a pedagogia como um território que se movimenta por entre formas e forças. Parte-se do entendimento de que as relações se estabelecem em um território, este não enquanto um "lugar geográfico", como nos aponta Zourabichvili (2004, p.46), mas justamente como um plano de pensamento que possui contornos próprios e que, por meio de sua movimentação entre formas e forças, cria modos de ser, estar e agir. Convivência tensa de um ao outro. De um ao outro porque não se vive só em um ou só em 
outro. Vive-se entre um e outro, nas errâncias dessa relação. Uma relação em movimento contínuo!

Forma como aquilo que é e que, por assim ser, pode ser identificada, reconhecida, significada. A forma é matéria territorializada (DELEUZE; GUATTARI, 1995) e dá-se por meio de um recorte do caos, matéria informe e virtual, para dar existência, tornar algo visível e dizível. "Estratificação" (DELEUZE; GUATTARI, 1995, p. 5), este movimento de dar forma aos fluxos e intensidades que atravessam as matérias não formadas, dando contornos para suas intensidades.

Formar uma forma é um movimento de atualização da matéria informe que constitui o universo. Tudo é informe até que algum agenciamento recorte uma parte desse informe, condicionando e agrupando seus fluxos a um determinado contorno. As formas não são estáticas, são e estão constantemente atravessadas pelas forças do plano em que estas mesmas formas foram atualizadas, fazendo-as variar. Compõem-se em uma dupla articulação, ora uma segmentaridade mais molecular, ora uma segmentaridade mais molar, uma na outra, constantemente, mesmo em um estrato bem definido (DELEUZE; GUATTARI, 1995).

Mas existem formas ou estratos que querem perpetuar-se e não se deixam atravessar pelos fluxos intensivos de (de)formação, que fazem parte do seu próprio movimento. Essas formas cavam territórios estratificados e codificados, "duro[s], molar[es] e organizado[s]" (DELEUZE; GUATTARI, 1995, p. 55), com movimentos de "centramento, unificação, totalização, integração, hierarquização, finalização" (Ibidem, p. 55). Formas que se constituem pela linguagem e que, com ela e por meio dela, delimitam cada vez mais seu território, com um determinado regime de signos que se efetivam em palavras de ordem (DELEUZE; GUATTARI, 1995b), agenciamento que atua sobre os corpos que circulam e são formados por essa forma, delimitando, direcionando e orientando modos de ser, agir e pensar dentro dos limites de um território físico e imaterial, em sua constante relação e interferência.

Da pedagogia como um território que possui suas funções e formações específicas, estas criam sua marca e o contorno do seu território, que opera em um plano de pensamento que se efetiva em lugares reais, como a escola, a sala de aula, o currículo. Lugares legítimos, legitimados e consagrados. Lugares inventados na Modernidade, da mesma forma que a própria pedagogia (NOGUERA-RAMÍREZ, 2011; GAUTHIER, 2013).

A pedagogia como território ensina e organiza o ensino; é a ciência que se ocupa em pensar a educação, os saberes, o tempo, o espaço. Profissão que é evocada quando se quer formar sujeitos, não só na escola, como também em outras instituições, extrapolando o contorno de seu domínio, inventado na Modernidade, ou seja, a escola e a sala de aula (DUSSEL; CARUSO, 2003).

Esse território ganha contornos precisos na Modernidade, no continente europeu, junto ao processo de laicização que cria condições de possibilidade para novas maneiras de 
pensar e compreender o mundo, provocando transformações em todos os âmbitos e implicando uma nova maneira de pensar os saberes pedagógicos (NOGUERA-RAMÍREZ, 2011). Mas se faz necessário uma observação! A pedagogia é muito relacionada à educação e aos processos de escolarização, mas é inventada a partir do momento em que a educação se torna um processo de massas, ou seja, quando esta é estendida para a população, não mais só para uma elite privilegiada; com isso, surge a necessidade de criar um aparato pedagógico que dê conta dessa massa, que precisa ser formada (DUSSEL; CARUSO, 2003; GAUTHIER, 2013). A educação fez e faz parte das diversas sociedades, mas a pedagogia não! Esse saber específico foi criado na Modernidade, com o objetivo de (trans)formar os modos de ensino existentes até o período de sua emergência.

\begin{abstract}
Por pedagogia entendemos a codificação de certos saberes próprios ao docente, isso é, um conjunto de regras, de conselhos metódicos que não devem ser confundidos com os conteúdos a ensinar, cuja formulação via o mestre para que o aluno aprenda um acervo maior de conhecimentos, mais depressa e em melhores condições (GAUTHIER, 2013, p. 105).
\end{abstract}

\begin{abstract}
[Pedagogia] como conjunto de saberes - saberes que dizem como se deve ensinar, como as pessoas apreendem, como devem funcionar as escolas para que a aprendizagem seja mais efetiva, quais os conhecimentos são mais relevantes para compor um currículo, como professoras e professores devem exercer seus ofícios, etc. (VEIGA-NETO, 2004, p. 65).

A pedagogia é uma ciência e uma arte; está associada ao "ensinar" e ao "educar". A pedagogia ocupa-se das "crianças". Neste caso, pode-se acrescentar que algumas versões contemporâneas sustentam que a pedagogia não se ocupa unicamente das crianças, mas há também uma pedagogia dos adolescentes, uma pedagogia dos adultos (DUSSEL; CARUSO, 2003, p. 20).
\end{abstract}

A pedagogia como território assume o papel de (trans)formar ao invés de (de)formar (DELEUZE, 2007). Na (trans)formação, substitui-se uma forma por outra, trocam-se figuras que se mantêm num determinado estrato e na estabilidade do mesmo (Trans)formar torna-se um imperativo no interior dos discursos que constituem e percorrem o território da pedagogia. Assim, ela é uma invenção muito bem inventada, porque, além de legitimar, também está legitimada, primeiro pelas escrituras sagradas e, depois, pelos desígnios da razão pura. Dupla articulação que se encontra incrustada no cerne da pedagogia, dando-lhe a precisão de suas formas historicamente construídas. Da pedagogia como um território com contornos precisos! Território com lugares reais/físicos que se efetivam por meio de um plano, antes, incorporal, que atua em virtualidade (de)limitando-os. Território que opera em um plano de pensamento específico, embora se articule com outros planos em uma relação de interferência. Seu plano, arquiteturalmente desenhado, ao articular-se com outros territórios, injeta neles modos de ser, estar, sentir, viver, da mesma maneira que é afetado por esses outros territórios. Uma relação de implicação e variação. Variação que mantém a estabilidade das formas, como também variações que (de)formam, criando outras formações.

Não se vive sem formas; sem elas, viveríamos em um mundo caótico e sem qualquer referência. O problema das formas é quando elas se estratificam e não se permitem 
movimentos que as abram para o fora, desestabilizando suas formações e criando vazios para novos e outros agenciamentos.

Alguns territórios carregam uma carga secular em suas formações, como o caso do território da pedagogia. Marcas seculares que, mesmo no passado, incidem sobre o presente. Um passado que retorna, muitas vezes, enquanto arquivo que percorre um estado presente e produz uma movimentação do mesmo.

A pedagogia, ao fazer-se pelo caminho, é afetada por ele e nele deixa seus rastros. Entre um território e seus rastros, seu deslocamento, com ritmos e velocidades variados, agencia a tensão das formas e forças que a constituem e a mantêm em movimento, mesmo que esta movimentação não seja perceptível a olhos nus. Um território sempre é atravessado por forças que variam suas formas, e o seu contrário também.

\section{UMA COMPOSIÇÃO: PEDAGOGIA E NOME PRÓPRIO}

Quando e como um território que possui um nome e uma movimentação legítima e legitimada pode/consegue falar em nome próprio? Conforme Deleuze e Guattari (1997, p. 51), não é "em função de uma forma [...] que um nome pode tomar um valor de nome próprio", mas justamente quando uma forma se deixa atravessar pela força dos encontros, que se sucedem em um percurso/travessia, que se torna possível falar em nome próprio. Porque "o nome próprio designa antes algo que é da ordem do acontecimento, do devir ou da hecceidade" (Ibidem, p. 52).

A necessidade de pensar uma pedagogia que fale em nome próprio aconteceu de um encontro com tal noção tomada por Deleuze e Guattari em composição com uma impossibilidade. Da impossibilidade como condição. Condição engendrada na necessidade de pensar de outros modos o território da pedagogia. Necessidade de invenção de outros jeitos de fazer pedagogia. Uma impossibilidade do corpo e do pensamento de mover-se por caminhos já, há muito, conhecidos. Estradas com coordenadas visíveis e previsíveis, rumo ao mesmo e ao uno.

Pensar de outros modos a pedagogia quer dizer engendrar movimentos por dentro dela na intenção de torná-la outra, dessemelhante de si. (Des)filiá-la de um passado secular que, muitas vezes, enrijece suas formas, não permitindo que forças a atravessem e criem novas e outras formações, mais efêmeras, que por meio de um movimento intensivo e incessante despersonalizem uma identidade inventada na Modernidade.

Não se propõe, em nenhum momento, pensar uma pedagogia que fale em nome próprio por meio de um apagamento da tradição de movimentos que já se fizeram e que constituem as formas e formações dessa pedagogia, mas muito mais "fazer fugir [...] fazer um sistema vazar" (DELEUZE; PARNET, 1998, p. 49) por meio da invenção de outros deslocamentos por entre essas formas e formações. Uma movimentação intensiva, portanto, 
muito mais por uma necessidade do que por uma obrigação, que ao acontecer borra algumas verdades que acabam por criar condições para que novas e outras formações se estabeleçam nesse território. Formações que também formam e criam formas, mas estas com contornos mais efêmeros porque os nomes próprios, conforme Deleuze (2006, p. 325), se aproximam de uma movimentação nômade.

Há uma espécie de nomadismo, de deslocamento perpétuo de intensidades designadas por nomes próprios, e que penetram umas nas outras ao mesmo tempo em que são vividas sobre um corpo pleno. A intensidade só pode ser vivida em relação com sua inscrição móvel sobre um corpo, e com a exterioridade movente de um nome próprio.

Dessa maneira, compreende-se que um nome próprio possui engendrado em si um movimento, mas este muito mais intensivo do que extensivo. Portanto, pensar uma pedagogia que fale em nome próprio passa por assumir essa movimentação intensiva como condição de possibilidade para a invenção de novos e outros deslocamentos por entre as diversas formas e formações de um território, neste caso, o território da pedagogia.

\section{NOTAS FINAIS}

A composição que se mostrou neste texto tornou-se possível por meio de uma necessidade de pensar diferentemente, pensar por outras vias e com outras matérias. Criar tensionamentos que fragilizassem os modos de deslocamentos perpétuos e perenes que percorrem e mantêm a estabilidade dos discursos e as formas de fazer e viver pedagogia. Uma movimentação que, ao deslocar a noção de nome próprio do plano filosófico para o plano onde opera a pedagogia, cria condições para essa composição que se propôs, por meio do pensamento, a desacomodar e inventar novas maneiras de viver e experimentar a própria pedagogia.

Para pensar e experimentar uma pedagogia que fale em nome próprio, não existe manual ou orientações precisas, até porque não se pretende que sua potência se torne outra forma e/ou outro imperativo. Mas talvez haja aí um desejo de percorrer de outros modos as várias formas e formações que constituem o território da pedagogia, buscando estranhá-las e, nesse processo, recolher aquilo que desacomoda e, com isso, fazer novas e outras composições.

Ao finalizar, conclui-se que as aproximações incomuns - nome próprio e pedagogia -, ao se efetivarem em texto, movimentaram o corpo e o pensamento, criando condições para um possível: viver e experimentar uma pedagogia que fale em nome próprio. 


\section{REFERÊNCIAS}

DELEUZE, Gilles. A ilha deserta: e outros textos. São Paulo: Iluminuras, 2006.

DELEUZE, Gilles. Conversações: 1972-1990. Tradução de Peter Pál Pelbart. Rio de Janeiro: 34, 1992.

DELEUZE, Gilles; PARNET, Claire. Diálogos. Tradução de Eloisa Araújo Robeiro. São Paulo: Editora Escuta, 1998.

DELEUZE, Gilles. Klossowski ou os corpos-linguagem. In: DELEUZE, Gilles. Tradução de Luiz Roberto Salinas Fortes. Lógica do sentido. São Paulo: Perspectiva, 2006b.

DELEUZE, Gilles. Francis Bacon: lógica da sensação. Rio de Janeiro: Jorge Zahar, 2007.

DELEUZE, Gilles; GUATTARI, Félix. Mil Platôs: capitalismo e esquizofrenia. Tradução de Aurélio Guerra Neto e Cecília Costa Pinto. Rio de Janeiro: 34, 1995.

DELEUZE, Gilles. Mil Platôs: capitalismo e esquizofrenia. Tradução de Ana Lúcia de Oliveira, Lúcia Cláudia Leão e Suely Rolnik. São Paulo: 34,1995b.

DELEUZE, Gilles. Mil Platôs: capitalismo e esquizofrenia. Tradução de Aurélio Guerra Neto, Ana Lúcia de Oliveira, Lúcia Cláudia Leão e Suely Rolnik. São Paulo: 34, 1996.

DELEUZE, Gilles. Mil Platôs: capitalismo e esquizofrenia. Tradução de Suely Rolnik. São Paulo: 34,1997.

DELEUZE, Gilles. Mil Platôs: capitalismo e esquizofrenia. Tradução de Peter Pál Pelbart e Janice Caiafa. São Paulo: 34, 1997b.

DUSSEL, Inés; CARUSO, Marcelo. A invenção da sala de aula: uma genealogia das formas de ensinar. São Paulo: Moderna, 2003.

GAUTHIER, Clermont. O século XVII e o nascimento da Pedagogia. In: GAUTHIER, Clemont; TARDIF, Maurice (Orgs.). A Pedagogia: teorias e práticas da Antiguidade aos dias atuais. 3. ed. Petrópolis: Vozes, 2013. p. 101-128.

NOGUERA-RAMÍREZ, Carlos Ernesto. Pedagogia e governamentalidade ou da modernidade como uma sociedade educativa. Belo Horizonte: Autêntica Editora, 2011.

VEIGA-NETO, Alfredo. Algumas raízes da pedagogia moderna. In: ZORZO, Cacilda; SILVA, Lauraci D.; POLENZ, Tamara (Orgs.). Pedagogia em conexão. Canoas: Editora da ULBRA, 2004. p. 65-83.

ZOURABICHVILLI, François. O vocabulário de Deleuze. Rio de Janeiro: Relume Dumará, 2004. 


\footnotetext{
excertos da expressão 'nome próprio' foram encontrados. GUATTARI, 1995b; DELEUZE, 2006b).

iii Platô 1. Introdução: Rizoma.

iv Acerca do Ritornelo.

v Platô 2. Um só ou vários lobos?

vi Platô 10. Devir-intenso, Devir-animal, Devir-imperceptível.

vii Platô 4. Postulados da Linguística; Platô 5. Sobre alguns regimes de signos.
}

' Esta obra, no Brasil, foi dividida em cinco volumes - 'Mil Platôs 1, 2, 3, 4, 5' -, mas a obra como um todo desenvolve-se por meio de vários textos, denominados 'platôs', que a compõem e conversam entre si. Dessa maneira, o livro 'Mil Platôs 1', por exemplo, compreende o platô 1. Introdução: Rizoma; Platô 2. Um só ou vários lobos; Platô 3. A geologia da moral. Em alguns momentos do artigo, será mencionado o platô onde os

ii Forma delimitada pela linguagem que dá contornos precisos ao sujeito, ao objeto, às coisas (DELEUZE;

ANA PAULA CRIZEL Mestre em Ensino e voluntária pelo Centro Universitário Univates UNIVATES, Lajeado, RS - Brasil E-mail: ana.crizel@gmail.com

ANGÉLICA VIER MUNHOZ Doutora em Educação Universidade Federal do Rio Grande do Sul - UFRGS, Porto Alegre, RS - Brasil.

Professora Titular Centro Universitário Univates, UNIVATES Lajeado, RS - Brasil. E-mail: angelicavmunhoz@gmail.com

Recebido em: 07/12/2015 Aprovado para publicação em: 20/03/2016

\section{Como citar este documento:}

CRIZEL, Ana Paula; MUNHOZ, Angélica Vier. Por uma pedagogia que fale em nome próprio. ETD - Educação Temática Digital, Campinas, SP, v. 18, n. 4, p. 942-954, nov. 2016. ISSN 1676-2592. Disponível em: 〈http://periodicos.sbu.unicamp.br/ojs/index.php/etd/article/view/8642175>. Acesso em: 16 nov. 2016. doi:http://dx.doi.org/10.20396/etd.v18i4.8642175. 